\title{
Anticipated Difficult Airway in Ear, Nose and Throat Procedures
}

Namita Mahesh Baldwa

\begin{abstract}
Contrary to general and obstetric populations, where difficult airway is widely studied and well documented, it requires further research in elective and emergency ear, nose and throat (ENT) surgeries. American Society of Anesthesiologists (ASA) has published practice guidelines for the management of difficult airway, which help us deal with it perioperatively. All patients posted for ENT surgeries with difficult airway should be evaluated preoperatively and the strategy for management of difficult intubation as well as extubation chalked out. In the event, that the primary approach fails, the secondary plan should always be clear preoperatively, to reduce morbidity and mortality.
\end{abstract}

Keywords: Difficult airway, Management, Predictors.

How to cite this article: Baldwa NM. Anticipated Difficult Airway in Ear, Nose and Throat Procedures. Int J Otorhinolaryngol Clin 2015;7(1):10-16.

\section{Source of support: Nil}

Conflict of interest: None

\section{INTRODUCTION}

Predicting difficult airway in general and obstetric populations is studied and well documented. ${ }^{1}$ However, there are few studies with respect to patients admitted for elective and emergency ear, nose and throat (ENT) surgeries. Some common underlying conditions that can cause difficulty in airway management include orofacial infection, trauma, tumors, and a history of previous surgery or radiotherapy to the head and neck. Difficult intubation may lead to increased morbidity and higher rates of unplanned critical care unit admissions. There are American Society of Anesthesiologists (ASA) guidelines which aid the management of the difficult airway and reduce the chances of adverse outcomes. The primary adverse effects associated with difficult airway include (but are not limited to) death, brain injury, cardiopulmonary arrest, unnecessary surgical airway, airway trauma, and damage to the teeth.

\section{Assistant Professor}

Department of Anesthesia, BYL Nair Hospital, Mumbai Maharashtra, India

Corresponding Author: Namita Mahesh Baldwa, Assistant Professor, Department of Anesthesia, BYL Nair Hospital Mumbai, Maharashtra, India, Phone: 09324288593, e-mail: drnamita_baldwa@rediffmail.com
American Society of Anesthesiologists defines difficult airway: Where an experienced provider anticipates or encounters difficulty with any or all of face mask ventilation, direct or indirect (e.g. video) laryngoscopy, tracheal intubation, supraglottic device (SGD) use, or surgical airway. Difficult tracheal intubation can be defined as one or all of the following: ${ }^{2}$

- Multiple attempts or more than one operator required;

- An adjunct, such as a tracheal tube introducer ('bougie') is required to facilitate tracheal intubation.

- An alternative intubation device is required after unsuccessful use of the primary device.

- Difficult supraglottic device use: Difficult or failed oxygenation and ventilation with an SGD may result from difficulties accessing the patient's mouth or hypopharynx, achieving a seal, or ventilating the lungs. ${ }^{3}$

- Difficult transtracheal surgical airway: A surgical airway can be achieved by percutaneous needle-guided cannula methods or by an open operative technique. A difficult transtracheal surgical airway is one that requires excess time or multiple efforts.

Failed airway: Defining a failed airway helps serve notice to the clinician that a different course of action may be needed to minimize the potential for harm to the patient:

- Failed tracheal intubation can be defined as failure to achieve successful tracheal intubation in a maximum of three attempts, irrespective of the technique(s) used.

- Failed oxygenation ('cannot intubate, cannot oxygenate' [CICO]) has occurred if, in the face of failed tracheal intubation, the patient cannot be successfully oxygenated by employing face mask or SGD ventilation. $^{4}$

Thus, the difficult airway represents a complex interaction between patient factors, the clinical setting, and the skills of the practitioner. The incidence of difficult intubation ranges from 1.5 to $20.2 \%$, with an overall incidence of $5.8 \%$. A higher incidence of difficult intubation in patients posted for ENT surgeries has been reported. ${ }^{5-7}$

\section{Common Causes of Difficult Airway in Patients Posted for ENT Procedures}

Abscesses involving the floor of the mouth: Patients might frequently have trismus which is less likely to be relieved 
with anesthetic induction. Here, the infective process affects the muscles of mastication; hence anticipated difficult intubation with preparation for fiberoptic intubation is advocated. Drainage of Ludwig's angina can be performed under local anesthesia but for extensive lesions, general anesthesia is advocated.

Periglottic tumors: These patients might be posted for diagnostic or therapeutic procedures under general anesthesia. Commonly performed procedures in these patients include direct laryngoscopy, microlaryngoscopy, etc. The difficulties encountered in these cases include airway obstruction, anticipated difficult intubation, preparedness for emergency surgical airway, shared airway surgery.

Radiotherapy to the head and neck: Is frequently associated with a difficult airway. Radiotherapy leads to increased vascularity, thrombi of vessels, blocked vascular and lymphatic outflow, increased vascular permeability, and edema which usually resolves after 1 to 2 months but may persist. ${ }^{8}$ Long-term changes include: altered soft-tissue structure (fibrosis, contractures and loss of elastic recoil), restricted neck extension, limited mouth opening, edema of the upper airway and salivary gland hypofunction. ${ }^{9-14}$ There might be associated trismus and increased risk of bleeding. Trismus is less likely to be relieved even after induction of anesthesia. In head and neck patients, tumor or dose-dependent irradiation of the pterygoid muscles and temporomandibular joint reduces mouth opening. Indirectly, limited neck movement secondary to radiotherapy further decreases the degree of mouth opening. These patients may pose difficulty for even placement of SGD insertion. Even after correct laryngeal mask airway (LMA) placement, failure to ventilate may be due to laryngeal collapse caused by the LMA compressing a rigid airway. Some studies have also reported difficult fiberoptic intubation in these cases due to laryngeal edema, or if the patient had a hoarse voice and stridor. ${ }^{15}$

\section{Management of Difficult Airway}

The American Society of Anesthesiologists has published practice guidelines for the management of difficult airway. The guidelines help to anticipate, prepare and manage difficult airway. The salient features are highlighted below. ${ }^{16}$

\section{Preoperative Assessment}

\section{Evaluation of the Airway}

\section{History}

The guidelines strongly recommend that an airway history should be conducted, whenever feasible, before the initiation of anesthetic care in all patients. This helps to detect medical, surgical, and anesthetic factors that may indicate the presence of a difficult airway. Studies report associations between several preoperative patient characteristics (e.g. age, obesity, obstructive sleep apnea, history of snoring) and difficult laryngoscopy or intubation. ${ }^{17-20}$ Difficult laryngoscopy or intubation is reported in a wide variety of acquired or congenital disease states (e.g. ankylosis, degenerative osteoarthritis, subglottic stenosis, lingual thyroid or tonsillar hypertrophy, Treacher Collins, Pierre Robin or Down syndromes). ${ }^{21-24}$

\section{Physical Examination}

The presence of upper airway pathologies or anatomical anomalies may be identified by conducting a preprocedure physical examination. The preoperative examination should include the parameters as included in Table 1. The guidelines strongly recommend that an airway physical examination should be conducted, whenever feasible, before the initiation of anesthetic care in all patients. Multiple features should be assessed during a physical examination. Reports indicate that certain diagnostic tests (e.g. radiography, computed tomography scans, fluoroscopy) can identify a variety of acquired or congenital features in patients with difficult airways. ${ }^{25-27}$

Table 1: Components of the preoperative airway physical examination $^{16}$

\begin{tabular}{|c|c|}
\hline Airway examination component & Nonreassuring findings \\
\hline Length of upper incisors & Relatively long \\
\hline $\begin{array}{l}\text { Relationship of maxillary and } \\
\text { mandibular incisors during normal } \\
\text { jaw closure }\end{array}$ & $\begin{array}{l}\text { Prominent 'overbite' } \\
\text { (maxillary incisors } \\
\text { anterior to mandibular } \\
\text { incisors) }\end{array}$ \\
\hline $\begin{array}{l}\text { Relationship of maxillary and } \\
\text { mandibular incisors during voluntary } \\
\text { protrusion of mandible }\end{array}$ & $\begin{array}{l}\text { Patient cannot bring } \\
\text { mandibular incisors } \\
\text { anterior to (in front of) } \\
\text { maxillary incisors }\end{array}$ \\
\hline Interincisor distance & Less than $3 \mathrm{~cm}$ \\
\hline Visibility of uvula & $\begin{array}{l}\text { Not visible when tongue } \\
\text { is protruded with patient } \\
\text { in sitting position (e.g. } \\
\text { Mallampati class }>2 \text { ) }\end{array}$ \\
\hline Shape of palate & $\begin{array}{l}\text { Highly arched or very } \\
\text { narrow }\end{array}$ \\
\hline Compliance of mandibular space & $\begin{array}{l}\text { Stiff, indurated, } \\
\text { occupied by mass, or } \\
\text { nonresilient }\end{array}$ \\
\hline Thyromental distance & $\begin{array}{l}\text { Less than three ordinary } \\
\text { finger breadths }\end{array}$ \\
\hline Length of neck & Short \\
\hline Thickness of neck & Thick \\
\hline Range of motion of head and neck & $\begin{array}{l}\text { Patient cannot touch tip } \\
\text { of chin to chest or can } \\
\text { not extend neck }\end{array}$ \\
\hline
\end{tabular}


In patients presenting for elective and emergency ENT surgery, in whom a difficult airway is anticipated, history of previous radiotherapy, the presence of airway symptoms, a reduced mouth opening and a reduced mandibular protrusion are independent predictors of a difficult intubation. ${ }^{28}$

Predictors of difficult face mask ventilation are: ${ }^{29,30}$

- Higher body mass index or weight

- Older age

- Male sex

- Limited mandibular protrusion

- Decreased thyromental distance

- Modified Mallampati class 3 or 4

- Beard

- Lack of teeth

- History of snoring or obstructive sleep apnea

- History of neck radiation Predictors of difficult supraglottic device use $\mathrm{e}^{31,32}$

- Reduced mouth opening

- Supra- or extraglottic pathology (e.g. neck radiation, lingual tonsillar hypertrophy)

- Glottic and subglottic pathology

- Fixed cervical spine flexion deformity Predictors of difficult direct laryngoscopy ${ }^{5,32-35}$

- Limited mouth opening

- Limited mandibular protrusion

- Narrow dental arch

- Decreased thyromental distance

- Modified Mallampati class 3 or 4

- Decreased submandibular compliance

- Decreased sternomental distance

- Limited head and upper neck extension

- Increased neck circumference

Predictors of difficult Trachlight ${ }^{\circledR}$ lighted stylet use ${ }^{36}$

- Thick neck

- Neck flexion deformity

- Large tongue/epiglottis Predictors of difficult cricothyrotomy ${ }^{37}$

- Difficulty identifying the location of the cricothyroid membrane:

- Female sex

- Age $<8$ years

- Thick/obese neck

- Displaced airway

- Overlying pathology (e.g. inflammation, induration, radiation and tumor).

- Difficult access to the trachea through the anterior neck:

- Thick neck/overlying pathology

- Fixed cervical spine flexion deformity.

\section{Basic Preparation for Difficult Airway Management}

Basic preparation for difficult airway management includes:
- Availability of equipment for management of a difficult airway (i.e. portable storage unit)

- Informing the patient with a known or suspected difficult airway

- Assigning an individual to provide assistance when a difficult airway is encountered

- Preanesthetic preoxygenation by mask

- Administration of supplemental oxygen throughout the process of difficult airway management. Opportunities for supplemental oxygen administration include (but are not limited to) oxygen delivery by nasal cannulae, facemask, or LMA insufflation; and oxygen delivery by facemask, blow-by, or nasal cannulae after extubation of the trachea.

Suggested contents of the portable storage unit for difficult airway management ${ }^{16}$

- Rigid laryngoscope blades of alternate design and size from those routinely used; this may include a rigid fiberoptic laryngoscope

- Videolaryngoscope

- Tracheal tubes of assorted sizes

- Tracheal tube guides: Semirigid stylets, ventilating tube-changer, light wands, and forceps designed to manipulate the distal portion of the tracheal tube

- Supraglottic airways (e.g. LMA or intubating laryngeal mask airway (ILMA) of assorted sizes for noninvasive airway ventilation/intubation)

- Flexible fiberoptic intubation equipment

- Equipment suitable for emergency invasive airway access

- An exhaled carbon dioxide detector.

\section{Strategy for Intubation of the Difficult Airway}

A preplanned preinduction strategy includes the consideration of various interventions designed to facilitate intubation should a difficult airway occur. This strategy will depend, in part, on the anticipated surgery, the condition of the patient, and the skills and preferences of the anesthesiologist. The recommended strategy for intubation of the difficult airway is highlighted in the ASA difficult airway algorithm as in Flow Charts 1A and B.

- An assessment of the likelihood and anticipated clinical impact of six basic problems that may occur alone or in combination:

- Difficulty with patient cooperation or consent,

- Difficult mask ventilation

- Difficult supraglottic airway (SGA) placement

- Difficult laryngoscopy

- Difficult intubation

- Difficult surgical airway access.

- Actively pursue opportunities to deliver supplemental oxygen throughout the process of difficult airway management. 
Flow Charts 1A and B: American Society of Anesthesiologists difficult airway algorithm

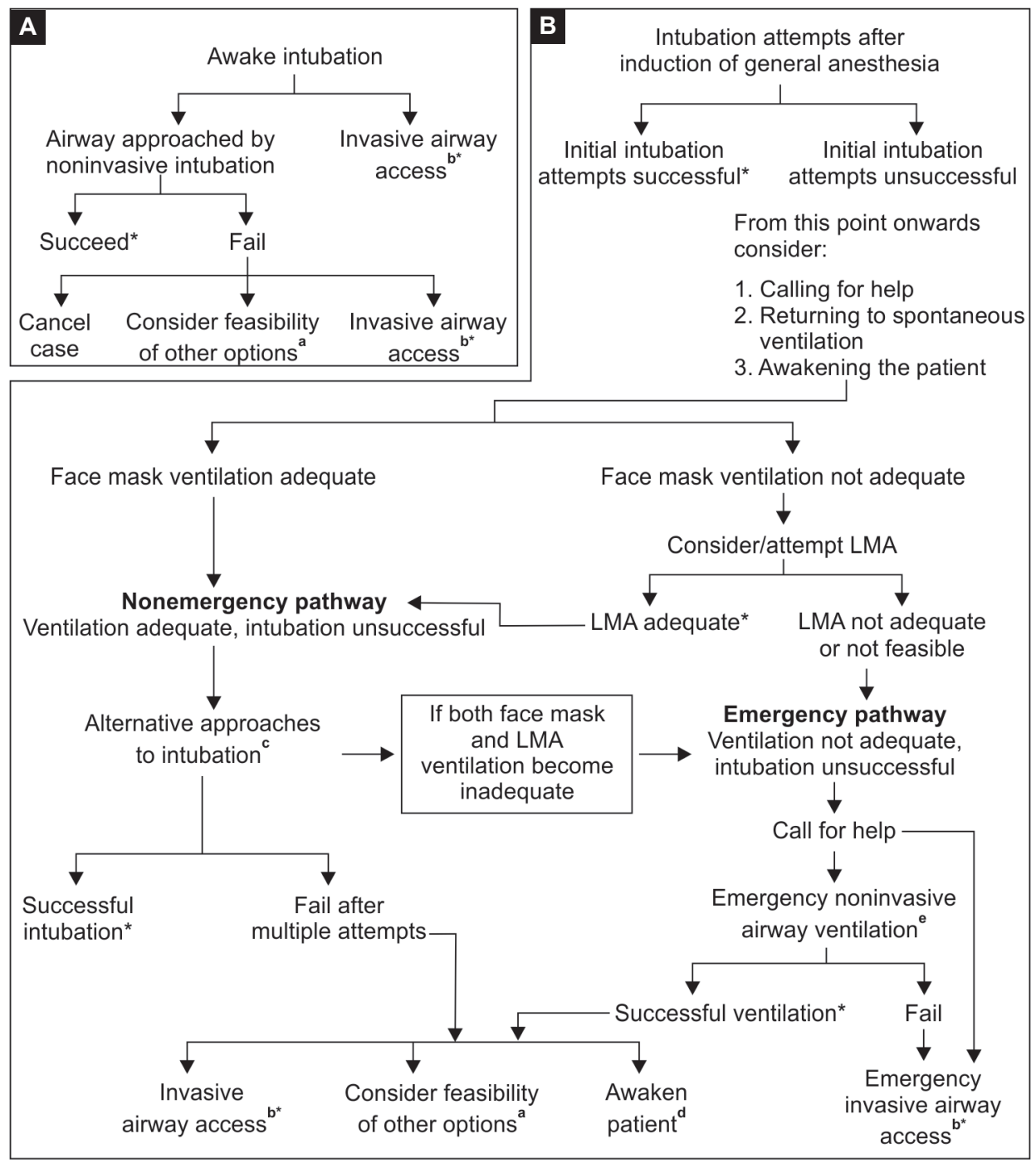

${ }^{*}$ Confirm ventilation, tracheal intubation, or LMA placement with exhaled $\mathrm{CO}_{2}:{ }^{\text {a Other options }}$ include (but are not limited to): Surgery utilizing face mask or anesthesia, LMA local anesthesia infiltration or regional nerve blockade. Pursuit of these options usually implies that mask ventilation will not be problematic. Therefore, these options may be of limited value if this step in the algorithm has been reached via the emergency pathway; ${ }^{b}$ Invasive airway access includes surgical or percutaneous tracheostomy or cricothyrotomy; ' ${ }^{\mathrm{A}}$ Alternative non-invasive approaches to difficult intubation include (but are not limited to): Use of different laryngoscope blades, LMA as an intubation conduit (with or without fiberoptic guidance), fiberoptic intubation, intubating stylet or tube changer, light wand, retrograde intubation, and blind oral or nasal intubation; ${ }^{\mathrm{d}}$ Consider re-preparation of the patient for awake intubation or cancelling surgery; ${ }^{e}$ Options for emergency non-invasive airway ventilation include (but are not limited to): Rigid bronchoscope, esophageal-tracheal combitube ventilation, transtracheal jet ventilation.

- A consideration of the relative clinical merits and feasibility of four basic management choices:

- Awake intubation vs intubation after induction of general anesthesia

- Noninvasive techniques vs invasive techniques (i.e. surgical or percutaneous airway) for the initial approach to intubation

- Videoassisted laryngoscopy as an initial approach to intubation

- Preservation vs ablation of spontaneous ventilation.
- Develop primary and alternative strategies, that is:

- The identification of a primary or preferred approach to:

- Awake intubation

- The patient who can be adequately ventilated but is difficult to intubate

- The life-threatening situation in which the patient cannot be ventilated or intubated.

- The identification of alternative approaches that can be used if the primary approach fails or is not feasible. Considering all the above challenges the various 
Table 2: Techniques for difficult airway management ${ }^{16}$

\begin{tabular}{|c|c|}
\hline Techniques for difficult intubation & $\begin{array}{l}\text { Techniques for difficult } \\
\text { ventilation }\end{array}$ \\
\hline Awake intubation & Intratracheal jet stylet \\
\hline Blind intubation (oral or nasal) & Invasive airway access \\
\hline Fiberoptic intubation & Supraglottic airway \\
\hline Intubating stylet or tube-changer & $\begin{array}{l}\text { Oral and nasopharyngeal } \\
\text { airways }\end{array}$ \\
\hline $\begin{array}{l}\text { Supraglottic airway as an intubating } \\
\text { conduit }\end{array}$ & $\begin{array}{l}\text { Rigid ventilating } \\
\text { bronchoscope }\end{array}$ \\
\hline $\begin{array}{l}\text { Laryngoscope blades of varying } \\
\text { design and size }\end{array}$ & $\begin{array}{l}\text { Two-person mask } \\
\text { ventilation }\end{array}$ \\
\hline \multicolumn{2}{|l|}{ Light wand } \\
\hline Videolaryngoscope & \\
\hline
\end{tabular}

techniques for management of difficult management are as highlighted in Table 2.

- The uncooperative or pediatric patient may restrict the options for difficult airway management, particularly options that involve awake intubation. Airway management in the uncooperative or pediatric patient may require an approach (e.g. intubation attempts after induction of general anesthesia) that might not be regarded as a primary approach.

- The conduct of surgery using local anesthetic infiltration or regional nerve blockade may provide an alternative to the direct management of the difficult airway, but this approach does not represent a definitive solution to the presence of a difficult airway, nor does it obviate the need for a preformulated strategy for intubation of the difficult airway.

- The strategy for intubation of the difficult airway should include confirmation of tracheal intubation (e.g. capnography).

\section{Patients having Obstructing Airway Pathology}

The patient with significant obstructing airway pathology may be maintaining airway patency only with considerable effort. Consultation with the attending surgeon and review of recent imaging studies (e.g. CT scans) is advisable prior to airway management. Nasopharyngoscopy may provide useful current information about the extent, location, and nature of obstructing or distorting pathology in the pharynx and larynx. ${ }^{38}$ Awake bronchoscopic intubation may be feasible for oral cavity and pharyngeal tumors. Although effective topical airway anesthesia may be difficult to achieve, friable tumors may bleed easily, anatomic landmarks may be obscured by edematous tissues, and bronchoscope manipulation around obstructing lesions can be challenging. Many such patients will have received radiation therapy to the upper airway or neck, rendering tissues friable or less compliant. Bulky lesions of the larynx may accommodate passage of a bronchoscope, although complete airway obstruction by the bronchoscope or the combination of the bronchoscope and tracheal tube may occur. Thus, awake tracheostomy or cricothyrotomy should be strongly considered as a primary technique for significant obstructing airway pathology.

Management of mid- or lower tracheal obstruction remains controversial. Rigid bronchoscopy and a skilled operator should be immediately available in case tracheal intubation fails to establish oxygenation. ${ }^{39,40}$ Cricothyrotomy or tracheostomy cannot be relied on to rescue a more distal airway obstruction.

\section{The 'Double Setup Airway Intervention'}

A 'double setup airway intervention' refers to the immediate availability of equipment and personnel capable of performing a surgical airway in the event that oxygenation fails for any reason during attempted tracheal intubation. Elements of the double setup include identification and marking of the cricothyroid membrane location, (sometimes with application of disinfectant solution to the neck and infiltration of local anesthetic into the overlying skin), ensuring cricothyrotomy equipment is in the room, and designation of an appropriately skilled individual to perform the procedure. In experienced hands, ultrasound may be helpful to identify the cricothyroid membrane, but there is no evidence to support its use in an emergency.

It should be emphasized that rapid cricothyrotomy is unlikely to succeed and cannot be regarded a prudent rescue option if access to the cricothyroid membrane is likely to be very difficult. This situation may mandate awake tracheostomy under local anesthesia as the preferred primary technique, performed by a surgeon under controlled conditions.

A double setup airway intervention should be prepared whenever the clinician considers a significant possibility of encountering a failed oxygenation situation during attempted awake or postinduction airway management.

\section{Strategy for Extubation of the Difficult Airway}

\section{ASA recommendations for extubation ${ }^{16}$}

The anesthesiologist should have a preformulated strategy for extubation of the difficult airway. This strategy will depend, in part, on the surgery, the condition of the patient, and theskills and preferences of the anesthesiologist. It includes:

- The relative merits of awake extubation vs extubation before the return of consciousness.

- General clinical factors that may produce adverse impact on ventilation after the patient has been extubated. 
- An airway management plan that can be implemented if the patient is not able to maintain adequate ventilation after extubation.

- Short-term use of a device that can serve as a guide for expedited reintubation. This type of device can be a stylet (intubating bougie) or conduit. Stylets or intubating bougies are usually inserted through the lumen of the tracheal tube and into the trachea before the tracheal tube is removed. Stylets or intubating bougies may include a hollow core that can be used to provide a temporary means of oxygenation and ventilation. Conduits are usually inserted through the mouth and can be used for supraglottic ventilation and intubation. The ILMA and LMA are examples of conduits.

\section{Recommendations for Follow-up Care ${ }^{16}$}

The anesthesiologist should document the presence and nature of the airway difficulty in the medical record. The intent of this documentation is to guide and facilitate the delivery of future care. Aspects of documentation that may prove helpful include:

- A description of the airway difficulties that were encountered at each step in airway management

- A description of the various airway managementtechniques that were used.

Notification systems, such as a written report or letter to the patient, a written report in the medical chart, communication with the patient's surgeon or primary caregiver, a notification bracelet or equivalent identification device, or chart flags, may be considered to be given to patient. The anesthesiologist should evaluate and follow-up with the patient for potential complications of difficult airway management.

\section{REFERENCES}

1. Shiga T, Wajima Z, Inoue T, Sakamoto A. Predicting difficult intubation in apparently normal patients: a meta-analysis of bedside screening test performance. Anesthesiol 2005; 103(2):429-437.

2. Crosby ET, Cooper RM, Douglas MJ, et al. The unanticipated difficult airway with recommendations for management. Can J Anaesth 1998;45(8):757-776.

3. Hung O, Law JA. Advances in airway management. Can J Anesth 2006;53(6):628-631.

4. Walls RM. The emergency airway algorithms. In: Walls RM, Murphy MF, Luten RC, Schneider RE, editors. Manual of emergency airway management. philadelphia: lippincott Williams \& Wilkins; 2004. p. 8.

5. Arne J, Descoins P, Fusciardi J, et al. Preoperative assessment for difficult intubation in general and ENT surgery: predictive value of a clinical multivariate risk index. Br J Anaesth 1998; 80(2):140-146.

6. Ayuso MA, Sala X, Luis M, Carbo JM. Predicting difficult orotracheal intubation in pharyngolaryngeal disease: preliminary results of a composite index. Can J Anaesth 2003;50(1):81-85.

7. Darshane S, Groom P, Charters P. Responsive contingency planning: a novel system for anticipated difficulty in airway management in dental abscess. Br J Anaesth 2007;99(6): 898-905.

8. Ward PH, Calcaterra TC, Kagan AR. The enigma of postradiation edema and recurrent or residual carcinoma of the larynx. Laryngoscope 1975;85(3):522-529.

9. Burkle CM, Walsh MT, Pryor SG, Kasperbauer JL. Severe postextubation laryngeal obstruction: the role of prior neck dissection and radiation. AnesthAnalg 2006;102(1):322-325.

10. August M, Wang J, Plante D, Wang CC. Complications associated with therapeutic neck radiation. J Oral Maxillofac Surg 1996;54(12):1409-1415.

11. Giraud O, Bourgain JL, Marandas P, Billard V. Limits of laryngeal mask airway in patients after cervical or oral radiotherapy. Can J Anaesth 1997;44(12):1237-1241.

12. Goldstein M, Maxymiw WG, Cummings BJ, Wood RE. The effects of antitumor irradiation on mandibular opening and mobility: a prospective study of 58 patients. Oral Surg Oral Med Oral Pathol Oral Radiol Endod 1999;88(3):365-373.

13. Sciubba JJ, Goldenberg D. Oral complications of radiotherapy. Lancet Oncol 2006;7(2):175-183.

14. Vissink A, Jansma J, Spijkervet FK, Burlage FR, Coppes RP. Oral sequelae of head and neck radiotherapy. Crit Rev Oral Biol Med 2003;14(3):199-212.

15. Schmitt HJ, Mang H, Schmidt J, Zenk J, Radespiel-Troger M. Fiberoptic intubation in patients after radiotherapy for carcinoma of the head and neck: difficulty and predictability. Eur J Anaesthesiol 2004;21(11):925-927.

16. Practice guidelines for management of the difficult airway: an updated report by the American Society of Anesthesiologists task force on management of the difficult airway. Anesthesiol 2013;118(2):251-270.

17. Domino KB, Posner KL, Caplan RA, Cheney FW. Airway injury during anesthesia: a closed claims analysis. Anesthesiol 1999;91(6):1703-1711.

18. Ezri T, Medalion B, Weisenberg M, Szmuk P, Warters RD, Charuzi I. Increased body mass index per se is not a predictor of difficult laryngoscopy. Can J Anaesth 2003;50(2):179-183.

19. Heinrich S, Birkholz T, Ihmsen H, Irouschek A, Ackermann A, Schmidt J. Incidence and predictors of difficult laryngoscopy in 11, 219 pediatric anesthesia procedures. Paediatr Anaesth 2012;22(8):729-736.

20. Juvin P, Lavaut E, Dupont H, Lefevre P, Demetriou M, Dumoulin JL, Desmonts JM. Difficult tracheal intubation is more common in obese than in lean patients. Anesth Analg 2003;97(2):595-600.

21. Buckland RW, Pedley J. Lingual thyroid-a threat to the airway. Anaesth 2000;55(11):1103-1105.

22. Coonan TJ, Hope CE, Howes WJ, Holness RO, MacInnis EL. Ankylosis of the temporomandibular joint after temporal craniotomy: a cause of difficult intubation. Can Anaesth Soc J 1985;32(2):158-160.

23. Nagamine $Y$, Kurahashi K. The use of three-dimensional computed tomography images for anticipated difficult intubation airway evaluation of a patient with Treacher Collins syndrome. Anesth Analg 2007;105(3):626-628.

24. Nakazawa K, Ikeda D, Ishikawa S, Makita K. A case of difficult airway due to lingual tonsillar hypertrophy in a 
patient with Down's syndrome. Anesth Analg 2003;97(3): 704-705.

25. Aoi Y, Kamiya Y, Shioda M, Furuya R, Yamada Y. Preanesthetic evaluation can play a crucial role in the determination of airway management in a child with oropharyngeal tumor. J Anesth 2006;20(3):215-219.

26. Fahy L, Horton WA, Charters P. Factor analysis in patients with a history of failed tracheal intubation during pregnancy. Br J Anaesth 1990;65(6):813-815.

27. Heindel DJ. Deep neck abscesses in adults: management of a difficult airway. Anesth Analg 1987;66(8):774-776.

28. Wong P, Parrington S. Difficult intubation in ENT and maxillofacial surgical patients: a prospective survey. The Int J Anesthesiol 2009;21(1):9.

29. Kheterpal S, Martin L, Shanks AM, Tremper KK. Prediction and outcomes of impossible mask ventilation: a review of 50,000 anesthetics. Anesthesiol 2009;110(4):891-897.

30. Gautam P, Gaul TK, Luthra N. Prediction of difficult mask ventilation. Eur J Anaesthesiol 2005;22(8):638-640.

31. Langeron O, Semjen F, Bourgain JL, Marsac A, Cros AM. Comparison of the intubating laryngeal mask airway with the fiberoptic intubation in anticipated difficult airway management. Anesthesiol 2001;94(6):968-972.

32. Ramachandran SK, Mathis MR, Tremper KK, Shanks AM, Kheterpal S. Predictors and clinical outcomes from failed laryngeal mask airway Unique ${ }^{\mathrm{TM}}$ : a study of 15,795 patients. Anesthesiol 2012;116(6):1217-1226.
33. Eberhart LH, Arndt C, Aust HJ, Kranke P, Zoremba M, Morin A. A simplified risk score to predict difficult intubation: development and prospective evaluation in 3763 patients. Eur J Anaesthesiol 2010;27(11):935-940.

34. Orozco-Diaz E, Alvarez-Rios JJ, Arceo-Diaz JL, OrnelasAguirre JM. Predictive factors of difficult airway with known assessment scales. Cir Cir 2010;78(5):393-399.

35. Reed MJ, Dunn MJ, McKeown DW. Can an airway assessment score predict difficulty at intubation in the emergency department? Emerg Med J 2005;22(2):99-102.

36. Hung OR, Pytka S, Morris I, Murphy M, Stewart RD. Lightwand intubation: II-clinical trial of a new lightwand for tracheal intubation in patients with difficult airways. Can J Anaesth 1995;42(9):826-830.

37. Elliott DS, Baker PA, Scott MR, Birch CW, Thompson JM. Accuracy of surface landmark identification for cannula cricothyroidotomy. Anaesth 2010;65(9):889-894.

38. Rosenblatt W, Ianus AI, Sukhupragarn W, Fickenscher A, Sasaki C. Preoperative endoscopic airway examination (PEAE) provides superior airway information and may reduce the use of unnecessary awake intubation. Anesth Analg 2011;112(3):602-607.

39. Patel A, Pearce A. Progress in management of the obstructed airway. Anaesth 2011;66(Suppl 2):93-100.

40. Cook TM, Morgan PJ, Hersch PE. Equal and opposite expert opinion. Airway obstruction caused by a retrosternal thyroid mass: management and prospective international expert opinion. Anaesth 2011;66(9):828-836. 